\title{
O ESPAÇO EXISTENCIAL EM XEQUE: UMA ODISSEIA PARA O ESPAÇO ONTOLÓGICO NA GEOGRAFIA ${ }^{1}$
}

\section{The existential space in check: an odyssey on to the ontological space in geography}

\author{
Humberto Goulart GUIMARÃES²
}

\section{RESUMO}

A Geografia acadêmica tem como pressupostos o impasse aristotélico-kantiano e o paradigma baconiano-cartesianonewtoniano. Destas problemáticas emerge um imbróglio lógico, remetendo o espaço a uma abordagem epistemológica, de característica externa à existência humana. Os frutos são as dicotomias: homem/natureza, homem/meio e homem/ espaço. O autor busca expressar algumas acepções críticas entrecruzando Geografia e Filosofia para a mudança do espaço existencial, colocando-o em xeque.

Palavras-chave: Espaço; Ser e Existência; Ontologia em Geografia.

\begin{abstract}
The academic Geography has as basis the Aristotelian-Kantian impasse and the baconian-cartesian-newtonian paradigm. From those problems emerges a logical complication, referring the space to an epistemological approach of external characteristics to human existence. The fruits are the dichotomies: man/nature, man/environnement and man/space. The author aims at expressing some critical conceptions relating Geography and Philosophy and puts in check the change of existential space.
\end{abstract}

Keywords: Space; Being and Existence; Ontology in Geography.

1 O presente artigo é o pressuposto dos debates teóricos de nossa abordagem mais concisa da Dissertação de mestrado intitulada: "Uma odisséia para o espaço: proposta de análise da existência espacial humana na Geografia", orientada pelo Professor Ruy Moreira (PPGEO/UFF).

2 Mestrando em Geografia pela Universidade Federal Fluminense (POSGEO-UFF). Professor I (Geografia - Ensino Fundamental) do Colégio Municipal Dr. Astério Alves de Mendonça - Rio Bonito, Brasil. E-mail: hugoulart_5@yahoo.com.br 
GUIMARÃES, H. G. O espaço existencial em xeque: uma odisseia para o espaço...

\section{INTRODUÇÃO}

Este artigo tem uma dupla intencionalidade. A primeira de cunho epistemológico, já a segunda abordando o que podemos tratar como uma proposta de análise crítica do espaço como modalidade ontológica do ser, buscando a verificação ontológica do homem ${ }^{3}$. A crítica epistemológica será menos averiguada do que a análise ontológica, contudo, isto não nos dá a impressão de uma negligência teórica com a primeira, mas sendo uma complementação, sobretudo crítica, do viés de análise Geográfico que há muito contribui com as externalidades (ou dicotomias científicas) metafísicas. Não somente nas entidades lógicas das ciências, mas, acima de tudo no estranhamento existencial do ser. Isto envolve acima de tudo uma odisseia para a humanidade e não somente para o espaço epistemológico. Expliquemos sumariamente tal relação.

$\mathrm{Na}$ Geografia oficial viemos pensando na maioria dos casos sobre "uma epistemologia do espaço" (SANTOS, 2007, p. 60), acreditando ser o seu maior problema a falta de um objeto, sendo a Geografia "viúva do espaço" (SANTOS, 1978). Não desmerecemos de forma alguma o trabalho árduo de $\mathrm{M}$. Santos e de inúmeros pensadores para a epistemologia da Geografia, mas, o que visamos é a luta por uma revolução da existência humana, não um imbróglio teórico academicista. $\mathrm{Na}$ Geografia o espaço é concebido ideologicamente, i.e., é um ente ideal produzido pela razão, como uma entidade lógica (SILVA, 1986). Como nos relembra Martins (2003), a ciência Geográfica está presa a um impasse aristotélico-kantiano, no qual "o fundamento lógico seria a lógica formal (Aristóteles) e a concepção de espaço advinda de Kant"(p. 41). Nesse sentido é que Silva (1988, p. 6) indaga-nos: "como resolver o impasse aristotélico-kantiano?". Pouco se tem feito, no mais reafirmamos o impasse, muitas vezes sem refutar, vendo o espaço como um conceito-chave na Geografia, em nossos ares (CORRÊA, 2003), ou, em trabalhos clássicos, atrelando ao caráter científico da Geografia o estatuto de ciência do espaço (HARTSHORNE, 2006) ${ }^{4}$. Nesse sentido é que o espaço está fora do lugar (SILVA, 1988), devemos ir ao seu lugar de busca, tratando-o como modalidade ontológica do ser. Assim, na Geogra- fia, tratamos de um homem atópico (MOREIRA, 1987), fora do mundo e do espaço, reforçando as dicotomias homem/natureza, homem/meio e homem/paisagem, através da máscara homem/espaço. A existência humana está, mas não é espacial.

Seguindo esta problemática é que surgem os "casamentos" feitos entre Filosofia e Geografia por Armando Corrêa da Silva (o lugar da busca). Fazer o que o mesmo chamou de "'pôr de pé' a reflexão filosófica a partir da preocupação do espaço como ser" (SILVA, 1988 , p. 127). Neste sentido é que caminha o nosso trabalho, indagamos sobre a possibilidade de se compreender o espaço como ser: revendo criticamente o espaço existencial (a forma como seu existencial). O espaço como existência do existente-humano. É em busca destas conexões que partimos, buscando compreender homem e espaço, como mundo do homem. Trabalhos recentes, abarcando ontologia e fenomenologia, vêm sendo tratados de forma altamente criativa e contributiva para a Geografia. Obras como de Moreira (1999, 2004, 2005, 2007, 2008), Martins (2007) e Lima (2007a, 2007b, 2008), não nos deixam sozinhos (GOULART GUIMARÃES, 2009) nesta busca.

Assim prosseguimos, com uma proposta crítica da epistemologia do espaço via do espaço ontológico na Geografia.

\section{O ESPAÇO METAFÍSICO: DO SENTIDO COMUM AO ESPAÇO GEOGRÁFICO}

Podemos abordar como sendo um sentido de ser comum, o ser simplesmente dado, absoluto com caráter metafísico (onto-teo-lógico), no qual cabe chamar de "senso-comum".

Este tratamento ingênuo dos fenômenos cotidianos como coisificação do sentido de ser, do homem, do mundo, do espaço. Cabe então expressar o "sensocomum" da ideia de espaço que povoa o nosso "mundo cotidiano". "Nós mesmos nos movimentamos no nível de compreensão do senso comum, na medida em que nos cremos em segurança no seio das 'verdades' da experiência da vida, e da ação, da pesquisa, da criação

3 O entrecruzamento crítico de método será na união pouco comum entre uma análise existencial-ontológica heideggeriana, com a ontologia do homem de Marx aparece como método de análise. A ligação é na existência como autocriação do homem e no copertencimento entre homem e mundo.

4 "A geografia aparece assim como uma ciência do espaço, em função do que ele oferece ou fornece aos homens e como uma ciência da conjuntura e do resultado das sucessões de conjunturas" (GEORGE, 1973, p. 16). 
GUIMARÃES, H. G. O espaço existencial em xeque: uma odisseia para o espaço...

e da fé" (HEIDEGGER, 1996, p. 154), basta olharmos para a acepção de espaço simplesmente dada, como um "campo" ou como um receptáculo. Hoje, cada vez mais, "em sociedades ocidentais, essa visão de espaço é instintiva na linguagem comum" (SMITH, 1988, p. 109). Forma-se na nossa presença cotidiana, um uso totalmente acrítico com relação à veiculação desta opinião "pública" de espaço. Este espaço é manejado dentro de um "grande corpo de costumes" que permeiam a subjetividade cotidiana. Quando temos a ideia formada de que uma área construída ou não, dizemos que "tem bastante espaço". Quando temos algum terreno, saguão de prédio ou área destinada a algum fim comercial, lá está: "espaço de lazer"; "espaço de cultura"; "espaço verde"; "espaço esotérico"; "espaço armazém"; "espaço aberto"; "espaço de dança"; "espaço de diálogo e prática"; "espaço AGB"; etc. E assim poderíamos quantificar inúmeras formas de ver esse espaço como área, receptáculo vazio, campo; com um sentido de ser simplesmente dado.

É interessante atentarmos-nos para os dois últimos exemplos: espaço de dialogo e prática, e espaço $A G B$. Pois bem, são formulações gerais explícitas em domínio "público" pela AGB (Associação de Geógrafos Brasileiros) para o XV Encontro Nacional de Geógrafos (ENG) do ano de 2008. Quando mandamos os nossos respectivos resumos e/ou trabalhos para o encontro, lá encontramos: "dê dois toques de espaço para o próximo parágrafo". Ora, este espaço do teclado representa um "vazio" entre os caracteres, ou seja, o senso-comum que "cospe" o "corpo de hábitos cotidianos" simplesmente dados é de domínio público e principalmente científico.

E nesse sentido, que "todo conhecimento científico visa constituir-se em senso comum", tornando o homem-comum um "ignorante generalizado" (SOUSA SANTOS, 2002, p. 55). E o "arauto e beneficiário dessa objetivação dos princípios universais da razão metafísica numa escala de espaço planetária" (MOREIRA, 2007, p. 140) é o modo de produção capitalista, que emerge assim como essa produção da ideia de espaço, a relação de externalidade entre o homem e o mundo. Este último, visto como circundante: um espaço metafísico.

Assim nossa existência acaba por ser simplesmente dada pelas apropriações da ciência. O espaço do senso comum está atrelado à abordagem e difusão científica lógica: ideo-lógica. Daí que advém a problemática da apropriação do que entendemos por espaço na Geografia. É assim que se torna premente "cada vez mais lançar-se à crítica desses conceitos fundamentais, para que não possamos ser inconscientemente governados por eles"(EINSTEIN apud SMITH, 1988, p. 109). O que temos então é o que podemos tratar como "o mal-estar espacial", este "determinado pelo modo de ser-estar-espacial criado como cultura no Ocidente, onde o homem está, mas não é espaço" (MOREIRA, 2007, p. 134). Fruto que é (este imaginário e discurso sobre o espaço) do modelo dominante de racionalidade, enraizado e unívoco da ciência moderna, o paradigma baconiano-cartesiano-newtoniano (GOULART GUIMARÃES, 2009).

Porém, este mal-estar espacial, no sentido de uma abstratividade do conceito de espaço, numa externalidade na relação entre homem e espaço, advém da antiguidade; mais precisamente da raiz judaico-cristã, que remonta à cultura judaica e se relaciona à metafísica rabínica ${ }^{5}$. E o conceito abstrato de espaço passa para a chamada "filosofia clássica", sendo o estamento científico e do senso-comum do conceito e ideia de espaço até os presentes dias. Aristóteles, em dois livros irá desenvolver o conceito de espaço: Categorias e Física IV. O primeiro "reafirma o conceito da metafísica rabínica", no segundo "define-o como o começo e o fim do corpo, quebrando com aquele conceito, trazendo-o para o plano dos corpos concretos e, no fundo, gerando um novo conceito" (MOREIRA, 2008, p. 57, grifos nossos).

E partindo destas duas acepções do espaçoaristotélico, emergem, na modernidade, dois conceitos de espaço contraditórios. É nesse ínterim que "surge" Descartes, se refazendo sob o primeiro e abstrato conceito de espaço da metafísica rabínica (o do livro Categorias), essencialmente onto-teo-lógica. O segundo, em contrapartida com Descartes, surge Leibniz, reafirmando o espaço de Física IV.

Basicamente então, Descartes vai pensar sua "ontologia do 'mundo'" (HEIDEGGER, 2008, p. 140) na extensio, transformando o conceito de espaço como dado puramente geométrico. E assim esse espaçogeométrico cartesiano é a determinação de um "mundo" como res extensa. Descartes distingue o ego cogito como res cogitans da res corpórea, separando assim corpo de "espírito". Separa homem-corpo de espaço,

5 Cabe ressaltar, para fins de maior detalhamento sobre as origens filosóficas da abstratividade do conceito de espaço, os trabalho de Moreira (2007 e 2008), mais precisamente no seu "O mal-estar espacial no final do século XX" no primeiro e, o capítulo "a abstratividade espacial: a evolução do conceito de espaço" em referência ao segundo, que se encontra em formato de artigo. 
GUIMARÃES, H. G. O espaço existencial em xeque: uma odisseia para o espaço...

criando uma espacialidade do mundo circundante, mas, não do homem. Este espaço geométrico é a extensão em comprimento, altura e largura. Temos assim dois sentidos de ser apartados: a res cogitans e a res extensa; homem-pensante e espaço-extenso que representa o mundo externo ao homem, que logo, não é responsável por nada neste mundo.

E assim que Descartes assume como método fundamental para a abstratividade do espaço-geométrico a Matemática, adota o modelo de rigor científico que "afere-se pelo rigor das medições" (SOUSA SANTOS, 2002, p. 15). O espaço metafísico cartesiano dá-se então "como campo-suporte da matematicidade do real" (MOREIRA, 2008, p. 58). Este espaço-cartesiano (res extensa), campo-suporte, é o "centro universal" da metafísica moderna, que se estabelece como prioridade enquanto fundamento da ciência. $E$ assim, como nos elucida Smith (1988, p. 111), parece-nos que "o espaço é simplesmente um dado universal da existência". No mote deste paradigma científico "surge" Isaac Newton, o inglês que nasce pouco antes da morte do Francês René Descartes (Newton nasce em 1643, Descartes morre em 1650), com interesses no conceito de espaço, que viesse dar "estatuto científico" para a Física, faz retorno às duas acepções contraditórias de espaçoaristotélico. E sua abstração espacial é baseada no que viria a se chamar de "mecânica newtoniana". Nela, "o mundo da matéria é uma máquina cujas operações se podem determinar exactamente por meio de leis físicas e matemáticas, um mundo estático e eterno a flutuar num espaço vazio, um mundo que o racionalismo cartesiano torna cognoscível por via de sua decomposição nos elementos que o constituem" (SOUSA SANTOS, 2002, p. 17).

O vínculo encontrado no espaço-cartesiano por Newton transforma a "sua física" como o "veículo de materialização". Para Newton existe o espaço absoluto e também o relativo. $O$ primeiro sendo dado primário (o espaço-extenso) campo suporte onde os entes irão formatar o relativo. Surge o espaço continente, em que o mundo não é espacial, está no espaço (MOREIRA, 2007). O mundo se dá como o espaço relativo, em que "o 'palco' do universo newtoniano, no qual ocorrem todos os fenômenos físicos, seria" (CAMARGO, 2005, p. 40) o espaço absoluto, continente e imutável. Assim a relação de externalidade entre o homem-corpo e espaço é afirmada. O homem ocupa lugar nesse espaço isotrópico que acaba se tornando o sujeito e arranjador da sua espacialidade. O homem-corpo se encontra como objeto do sujeito espaço, como um ser simplesmente dado, imutável e determinante do mundo do homem.

Este duplo que se estipula através do paradigma moderno de espaço, absoluto-relativo, é a formulação do espaço científico (portanto lógico) fundado no modelo metafísico cartesiano-newtoniano. E este duplo é que vem a ser apropriado pela Geografia, transfigurado com o nome de espaço geográfico. A "relação entre objetos, a qual existe somente porque os objetos existem e se relacionam" (HARVEY, 1980, p. 4-5) em um espaço receptáculo, o absoluto, é o espaço geográfico. Duas são as principais causas desta apropriação da Geografia. Primeira, pela tendência científica moderna estar tendo como debate a acepção de espaço e, como o "estatuto de ciência" é veiculado pelo paradigma das ciências físicas e naturais, adequando-se os fenômenos de superfície (relações entre objetos: o espaço relativo) ao espaço-continente (absoluto). Pronto! Como num "toque de mágica" surge o espaço geográfico que "é manifestadamente físico" (SMITH, 1988, p. 120). Segundo pelos princípios de Immanuel Kant (nascendo em 1724, três anos antes da morte de Newton), no qual "as implicações para geografia são ainda mais fundas, pois estão relacionadas ao espaço no processo de cognição dos fenômenos" (MARTINS, 2007, p. 36).

Esta "herança kantiana" é trazida para a Geografia através do alemão Alfred Hettner. Este último estudou Filosofia e Geografia, por isto do "casamento" das ideias de Kant sobre o espaço serem adaptadas pelo mesmo. Richard Hartshorne, discípulo das ideias de Hettner, confirmando a Geografia como "ciência do espaço", principalmente do espaço kantiano, vem a escrever o seu livro "Propósitos e natureza da Geografia" com base em postulados de Hettner sobre a superfície terrestre e, o artigo "O conceito de Geografia como uma ciência do espaço, de Kant e Humboldt para Hettner". Ratifica as bases herdadas de Hettner quanto a Geografia como ciência do espaço. É conveniente lembrar que os problemas da adaptação do espaço kantiano à Geografia junto com o "modismo científico" do duplo absoluto-relativo cartesiano-newtoniano, são frutos de uma interpretação fragmentada da obra de Immanuel Kant, no qual somente foram buscadas conciliações das acepções de espaço do filósofo com o que era "científico"; principalmente através da "primeira crítica". Sua obra mais utilizada, "Crítica da razão pura" (de 1781) possui uma acepção do espaço como um "dado a priori necessário à razão, sem o qual não seria cognoscível" (KANT, 1965, p. 36) o espaço material. 
GUIMARÃES, H. G. O espaço existencial em xeque: uma odisseia para o espaço...

Em "Crítica da razão pura” temos em sua estética transcendental do espaço, que começa tratando o mesmo no sentido de que "não pode ser considerado como algo interior em nós outros" (KANT, 1965, p. 33). Continua sua explanação ressaltando a exposição metafísica do espaço, no qual "o conceito apresenta como dado 'a priori'" (KANT, 1965, p. 34), considerado que é como "a condição da possibilidade dos fenômenos" (KANT, 1965, p. 35) como uma "grandeza infinita dada". O espaço aparece assim no "primeiro Kant" como o que "compreende todas as coisas que nos aparecem exteriormente", sendo estas "como fenômenos externos, que estão justapostas no espaço" (KANT, 1965, p. 3839, grifos nossos). Fechemos as ideias de Kant então com duas citações imprescindíveis do texto "Introdução à Geografia", onde, para o filósofo "a geografia [Die Geographie] se refere aos fenômenos que, em relação ao espaço, acontecem ao mesmo tempo [zu gleicher Zeit]" (KANT, 2008a, p. 125) e "o todo é o mundo, o cenário [Schauplatz] no qual nós realizamos todas as experiências" (KANT, 2008a, p. 123).

Notemos que esta adaptação, como que fazendo "nascer o espaço geográfico", irá causar problemas de interpretação e crises paradigmáticas na própria Geografia. Não tivemos momentos de crise epistemológica e ontológica na Geografia, mas sim, uma constante crise em movimento pela sua apropriação abstrata do homem em relação com o espaço. Este espaço geográfico nada mais é que "um espaço-estar, negador de um espaço-ser" (MOREIRA, 2008, p. 61). O espaço geográfico surge como um ente, em constante processo de ordenamento e subjugação do homem como seu prisioneiro. A frase explicitada na contracapa da primeira edição de "Por uma Geografia Nova" de Santos (1978), nos comprova a entidade do espaço com a máxima: "o espaço é a casa do homem e também sua prisão". Casa de um homem visto somente como habitante de um espaço continente (absoluto), e prisão porque visto como externo ao próprio homem. Na verdade não há relação, o homem é visto na Geografia como apartado do espaço, tido como conceito-mor que serve para arranjar, ordenar, formar, distribuir, estruturar, ao modo de instância que governa externamente a vida humana. O sentido de ser do homem não pertence ao homem na Geografia, e sim ao espaço, como sentido de ser dado.

Ora, acabamos por parecer estarmos localizados nesse espaço receptáculo, e não termos um sentido de ser espacial. O homem é sujeitado como objeto das "ações espaciais". No mundo fragmentado tal qual vivemos o ente humano é o mais puro objeto, o espaço sim é "palco" e também "ator", emergindo a máxima de que "o espaço interfere no devir dos homens" (SOUZA,
1986, p. 76). Temos a autocrítica, no sentido de que "em muitos trabalhos geográficos o espaço assume equivocadamente o papel de agente, restringindo as pessoas a meros espectadores, como se vivessem enclausuradas e estáticas nos lugares, imóveis nos encraves territoriais, inertes na paisagem" (LIMA, 2007a, p. 2). Qualquer conceituação que seja é vítima deste agente e palco em si. Este é um espaço que foge ao real, no que Santos (2007, p. 40) repudia com uma autoavaliação crítica da Geografia acadêmica: "o espaço dos geógrafos acabou por ficar tão fragmentário quanto o espaço fetichizado e a Geografia tornou-se ideológica, hostil ao real". O mesmo autor tratou o espaço como instância ou estrutura da sociedade, dotada de tal dinamismo e intencionalidade próprias, que se reveste de autonomia, segundo leis próprias (SANTOS, 1988b, p. 15) que governam a vida humana, deixando o homem à revelia, como um "elemento do espaço" (SANTOS, 1985).

Outras citações podem ser postas para reafirmar o paradigma dominante na Geografia. Claval em seu livro "A nova Geografia", utiliza títulos e frases que revelam o dado empírico do espaço (duplo) absolutorelativo. Vejamos nos títulos: "O indivíduo no espaço" e "A sociedade no espaço"; além de citações como: "as relações do homem com o seu suporte" (CLAVAL, 1982, p. 60), e, "o universo em que o homem se desloca é limitado [...] o indivíduo opta no espaço que a sua experiência anterior lhe fez conhecer" (CLAVAL, 1982, p. 64). Também George (1969, p. 30, grifos nossos) em seu capítulo específico sobre o espaço expressa: "toda coletividade humana se projeta sobre uma parcela do espaço terrestre que, sob formas diferentes, serve de base a suas atividades". Ou então, temos Lacoste (1977, p. 243, grifos nossos) com a orientação para "a reflexão sobre a prática daqueles que têm poder sobre o espaço", finalizando com Soja (1993, p. 101-102), expondo que "o espaço socialmente produzido é uma estrutura criada", uma "segunda natureza que se transforma no sujeito e no objeto geográficos da análise histórica materialista, de uma interpretação materialista da espacialidade". Estas citações, de Geógrafos acadêmicos, demonstram a clivagem-dominância do pensar das ciências ao senso-comum e à Geografia. E que trazem a "fórmula" espaço $\rightarrow$ homem, como condição da existência deste homem. Um espaço-produto externo ao homem, apartado no nosso dia a dia da copresença cotidiana e nas ciências. Faz-se necessário uma nova forma de pensar o espaço.

Para isto cabe expressarmos a formulação de novas ideias, para termos "quebras" da fórmula espaço $\rightarrow$ homem! 


\section{O ESPAÇO ONTOLÓGICO: A EXISTÊNCIA ESPACIAL HUMANA}

Temos então a busca da "quebra da fórmula" absoluta e sacralizada que aprisiona a análise crítica da existência humana via do espaço. Mas para tal expressemos primeiro, duas bases para adentrarmos neste projeto. Estas bases vêm de filósofos que foram, ora esquecidos, ora não interpretados. São eles, no caso do esquecido, Gottfried Leibniz, e como não interpretado, Immanuel Kant, principalmente o "Kant da terceira crítica".

Leibniz irá contra o pensamento de Descartes, principalmente, em sua apropriação do espaço-aristotélico. Leibniz buscará entendimento nas ideias do livro Física IV (diferente de Descartes que se baseia em Categorias). Neste livro o espaço será começo e fim do corpo, e é aí que Leibniz irá formular seu conceito de espaço, com base na "teoria das mônadas". Surge o espaço-monadológico. Contudo, ele está na contramão do pensamento científico, que vai tomando como base o rigor matemático do espaço-geométrico (absoluto) cartesiano; ora, por esse motivo Leibniz torna-se esquecido. Kant, como ressaltamos, foi não interpretado. Escolhemos o não em lugar do mal para dar ênfase ao sentido de que a sua "terceira crítica", tanto no âmbito da filosofia quanto no das ciências (em nosso caso, principalmente da Geografia), não foi levada a cabo de interpretação do espaço. Somente foi exaustivamente analisado o espaço a priori e externo da "Crítica da razão pura", não o de sua "Crítica da faculdade do juízo". Nesse sentido é que Kant não foi interpretado.

Comecemos pela releitura de Kant. Para tal, citemos uma das passagens finais de sua obra.

[...] Considere-se que a força motora que atribuo é uma força de repulsão. Nesse caso o corpo recebe (enquanto eu ainda não coloque ao seu lado nenhum outro corpo contra o qual ele exerça essa força) um lugar no espaço, mais ainda, uma extensão <Ausdehhnung>, isto é, espaço nele mesmo, e além disso o preenchimento do mesmo através das forças repulsoras das suas partes. E finalmente recebe também a lei deste preenchimento, que consiste no seguinte: a razão da reclusão das partes tem que decrescer na mesma proporção em que cresce a extensão do corpo e aumenta o espaço que este preenche com as mesmas partes através desta força (KANT, 2008b, p. 322).

Atentemos para as seguintes palavras: corpo, espaço, extensão, preenchimento e partes. Nessa reformulação da acepção kantiana de espaço, o corpo, recebe um lugar no espaço, mas é também extensão, ou melhor, tem-se a relação espaço corpo. Corpo é espaço extensão nele mesmo. A abstração do espaço em relação ao corpo é desconstruída, pois a cada extensão do próprio corpo (pois não é mais o espaço externo que é extenso) aumenta-se espaço. Esse espaço kantiano é homem (corpo) espaço. Não há apartamento nem dominação, a extensão do corpo é a do espaço e viceversa. Porém, a problemática do homem como sujeitado pelo espaço ainda não é resolvida.

Voltemos-nos agora para o espaço em Leibniz. Nele "a individualidade das mônadas, unidades de potência e ato no sentido da tradição aristotélica, não obedece qualquer extensão geométrica" (MOREIRA, 2008, p. 59). Buscando semelhanças no espaço-corpo kantiano, em Leibniz, o espaço começa e termina nos corpos. Mônada que em grego significa unidade e também separado (unidade-separado) é a substância da qual Leibniz vai buscar a substancialidade. As relações espaciais estão assim em constante movimento. As mônadas em movimento têm-se a ruptura com a ideia de unidade-movimento-separado. Nesse sentido "as mônadas, as unidades, os pontos, não necessitam da união, mas são aquilo que dá unidade. São capazes de algo" (HEIDEGGER, 1996, p. 203). A análise das mônadas feita por Heidegger assume um caráter ontológico, quando diz que "se cada ente, cada mônada tem a pulsão de si, isto significa que carrega a partir de si o essencial de seu ser, daquilo por que e o modo como exerce a pulsão" (1996, p. 206).

Finalizando, se transpusermos para a palavra ente o homem-corpo, teremos que a existência humana tem o essencial de seu ser. Ora a essência do ente humano é se relacionar com seu sentido de ser, dá-se a sua existência. Com essas duas interpretações espaciais temos abertura para um espaço não externo, mas corpóreo (e não como coisa extensa), não condicionante do homem, porque dele não se encontra apartado. Não temos mais a acepção do espaço absoluto-relativo que domina o devir humano, na expressão espaço $\rightarrow$ homem. Temos agora a acepção do ente composto homemespaço. Entendamos então estas análises a partir da acepção do espaço relacional, como um termo que abarque essa ruptura do pensamento não espacial do homem-corpo.

Nesse sentido é que Harvey $(1980$, p. 5) irá se apropriar traçando o "espaço relacional", esta acepção do "espaço tomado, a maneira de Leibniz, como estando contido em objetos, no sentido de que um objeto existe somente na medida em que contém e representa dentro de si próprio as relações com outros objetos". Sendo mais complexo no que "cada elemento reflete dentro de si todas as características da totalidade" (HARVEY, 
1980 , p. 250). Seguindo este pensamento é que Silva (1982) irá propor o "espaço ontológico" tendo como ponto de partida o espaço relacional de Harvey, em uma solução pluralista buscando no espaço relacional a complexidade da totalidade, que se manifesta empiricamente como espaço-superfície. Este espaço relacional é a representação da ruptura com a dicotomia: absoluto-relativo. É a busca de entendimentos complexos e compostos de espaço como: parte-todo, homem-espaço, sujeito-objeto. Todas como expressões compostas e não contraditórias.

Esbocemos rapidamente algumas ideias, que se reforçam com a acepção do espaço relacional, e o estatuto fenomenológico do composto parte-todo. Este estatuto, que busca fazer uma releitura de autores e suas análises geográficas.

Algumas ideias que "casam" com a de espaço relacional são vistas em outros autores de formas diversas, porém semelhantes como: "espaço inter-relacional" ou "espaço interconectado" em Massey (2008, p.105); em Mabogunje (apud SANTOS, 1988a, p. 26) "onde o espaço é representado como conteúdo e representando no interior de si mesmo outros tipos de relação que existem entre objetos"; e, no "espaço heterogêneo e relacional das heterotopias de Foucault" (SOJA, 1993, p. 26). As citações acima servem para reafirmar a acepção do relacional como ponto de partida para a ruptura do duplo absoluto-relativo, buscando a composição partetodo, com uma interconectividade, compreendendo nesse espaço a inter e intraconectividade dos fenômenos. Temos então a ideia de parte-conexão-todo, que se expressa na totalidade. A buscando o entendimento do espaço totalidade ${ }^{6}$.

Como compreendemos que, nesse espaço relacional é possível analisarmos a inter e intraconectividade dos fenômenos, faz-se mister uma releitura de autores que trabalharam classicamente a complexidade fenomenológica do mundo do homem. A busca pela totalidade dos fenômenos na Geografia, nas ciências perdeu totalmente o interesse teórico, pois o empírico recortado, na busca do cientificismo (o rigor do método científico de herança cartesiana) sobre o recorte do recorte do recorte criou uma visão fragmentada da realidade, coisa que era inimaginável na Geografia que inicia o século $\mathrm{XX}$. Voltemos para isso a alguns autores específicos.
O primeiro, Brunhes (1962, p. 52), que na sua proposta sobre uma "Geografia Humana" expõe a ideia do "todo terrestre", diz que na sua realidade geográfica os fenômenos devem ser estudados em suas múltiplas conexões. Ora, esta é a acepção de totalidade em Brunhes, e mais, o mesmo expressa que "fenômenos humanos, como todos os fenômenos terrestres, nunca permanecem idênticos a si mesmos. Todos são animados por determinado movimento; é necessário estudá-los como se estudam corpos em movimento". Este é o composto parte-conexão-todo em Brunhes. O estudo dos corpos em movimento lembra e muito tanto o espaço-corpo kantiano quanto o espaço monadológico de Leibniz. O segundo é Hartshorne, que busca o entendimento da "superfície da terra" em seu livro "Propósitos e Natureza da Geografia". Unindo a concepção das "combinações integradas de fenômenos inter-relacionados espacialmente" (1978, p. 40), assim também propõe que "as características intrínsecas da geografia são o produto dos esforços dos homens para conhecer e compreender as combinações de fenômenos tal como eles existem numa inter-relação de áreas em seu mundo" (HARTSHORNE, 2006, p. 31, grifos nossos). Atentemos para os dois grifos, trata Hartshorne dos fenômenos do mundo-do-homem, a Geografia buscando o sentido de ser. Temos então, uma proposta metodológica, próxima da de Brunhes, porém longe da estudada na Geografia na virada de século. O terceiro é George, em dois momentos, um como questão metodológica, e outro, como busca no entendimento da existência humana. George (1973, p. 15) trata primeiramente do que ele chama "do fenômeno 'secular' como fenômeno 'quotidiano'", e no outro momento com dois temas "existenciais". O trabaIho visto por George "como fator de produção e modo de existência, envolvendo a ação dos grupos humanos em quadros temporais definidos com base na forma do meio em que vivem e desenvolvem sua atividade" (1969, p. 93). Dando sequência ao tema, trata da existência, que para o Geógrafo, não deve ser abordada "antes do exame das formas de trabalho", pois, "sob a designação de existência deverão ser examinadas todas as modalidades da vida" até "as necessidades do consumo cotidiano" (GEORGE, 1969, p. 133). Fica bem claro nas propostas de análise de George nestas obras, que suas bases são: a existência, o trabalho e o cotidiano, como

6 Em nosso entendimento, utilizando de colocação de Silva (1982, p. 77), a solução do espaço relacional "não se põe como ser", não resolvendo o problema teórico. Assim é que buscamos através do espaço como totalidade, a composição parte-conexão-todo, no qual o todo é a parte e a aparte é o todo. Deste modo o espaço totalidade emerge como mais do que a soma das partes e mais do que o todo; parte-se então para a superação da dicotomia sujeito/objeto via do espaço ontológico. 
GUIMARÃES, H. G. O espaço existencial em xeque: uma odisseia para o espaço...

"fenômeno secular".

Outro autor, num sentido mais existencialontológico humano é Reclus, com a proposta-título de que "o homem é a natureza adquirindo consciência de si própria" (RECLUS, 1984). Elegendo como categoria principal de seu trabalho o homem. Dois autores mais recentes, e bem afamados em nossos estudos contemporâneos, como referência são: Yves Lacoste e Milton santos. Ambos podem ser relidos, sob o viés do espaço relacional. De Lacoste tomamos a espacialidade diferencial, não somente em referência ao seu "jogo" de escalas, mas por casarmos esta ideia com a complexidade dos fenômenos, casando como recurso de método a espacialidade diferencial como conexão, para que seja possível o entendimento da composição parte-todo. E assim como Armando C. da Silva (1982, p. 78), concordamos que "a contribuição de Lacoste, que julgo importante, é a desmistificação do reducionismo geográfico: o todo é, desde logo, complexo. Essa complexidade é, então, desdobrada analiticamente" via da espacialidade diferencial, que nos permite analisar fenomenologicamente o mundo do homem, conectando parte-todo.

É assim que podemos fazer a releitura de Santos, que tratou a totalidade espacial em "Por uma Geografia Nova" (1978) e "A Natureza do Espaço" (2006) e "Economia Espacial" (2003). No último, Santos propõe uma "fenomenologia do espaço" para podermos apreender o que ele trata como "a totalidade do diabo". O estudo da totalidade serviria assim como arcabouço que conduziria a "uma escolha de categorias analíticas que devem refletir o movimento real da totalidade" (2003, p. 199). Outra proposta parte de que "um caminho seria partir da totalidade concreta como ela se apresenta neste período de globalização - uma totalidade empírica - para examinar as relações efetivas entre a Totalidade-Mundo e os Lugares" (SANTOS, 2006, p. 115). Nessa busca pela realidade da totalidade empírica é que temos a acepção de Silva, caracterizando o empírico do espaço relacional como o "espaço-superfície", onde "os fenômenos geográficos podem se encontrar dispersos, concentrados, contínuos ou descontínuos na superfície do globo" (1988, p. 12). Sendo também a superfície como "o espaço comum do metabolismo da vida e da geografia", como uma "unidade holista" (MOREIRA, 2007, p. 126-127). Porém, o que nos indaga a existência é a particularidade, "como expressão da totalidade" (SILVA, 2000, p. 12), logo a análise ontológica recai ao homem e não ao espaço, recai no ente composto homem-espaço, que expressa a nossa visão de parte-conexão-todo.

Desta forma é que o empírico do espaço relacional é o espaço-superfície, no qual se realizam os fenômenos, mas com a análise existencial-ontológica sendo sobre o homem, busca-se o entendimento do espaço ontológico, o espaço como existencial da existência humana: o espaço como ser. Surge então a conexão entre parte e todo, entre corpo e superfície, homem e mundo. Este homem como expressão da totalidade e a Totalidade-Mundo como mundo do homem. Ora, se o que nos interessa é a particularidade como homemcorpo e sua existência espacial via dos fenômenos cotidianos, cabe outro entendimento da espacialidade, que não aquela segundo Descartes que constitui o mundo circundante. Este "mundo" como res extensa que nos vêm dando muitos trabalhos. Este é o "ponto negativo" de apoio à explicação de espacialidade (HEIDEGGER, 2008, p. 140). Busquemos então outros sentidos de espacialidade, que seja humana e não apartada deste sentido. Próxima da espacialidade de Merleau-Ponty, no qual "'o espaço é existencial' e 'a existência é espacial"' (CERTEU, 2002, p. 202), onde "o corpo próprio está no mundo assim como o coração no organismo" (MERLEAU-PONTY, 2006, p. 273).

Busquemos também uma espacialidade que entenda primeiramente o fenômeno de apartamento do homem do mundo e de si mesmo, uma espacialidade não somente "negativa" na ciência e no senso-comum, mas também na vida prática da coexistência cotidiana do trabalho. Uma espacialidade que desvele o sentido de ser-sendo humano. É em busca disto que partimos. Partimos então do espaço relacional, que na sua conexão entre contendo-contido, nos dá a ideia de espaço como totalidade. Assim é que vemos nessa totalidade espacial o homem e seu mundo de relações fenomênicas. O homem pode ser ver contido e contendo o mundo como mundo do homem, uma relação aonde "o todo é a parte e a parte é o todo" (SILVA, 1992, p. 109). Nesse movimento de conexão existencial do homem com o mundo é que temos a espacialidade. Porém tomamos como princípio o homem como parte, expressão que é da totalidade. Queremos então com isso entender que "a espacialidade não é apenas dos objetos. Há o espaço do corpo e seus prolongamentos" (SILVA, 2000, p. 18), do qual tomamos como sentido de corpo como o ente humano, o homem-corpo, que possui uma espacialidade, que é extensa e se dá por seus prolongamentos, a espacialidade além do corpo do homem, porque espacialidade criada e externalizada 
GUIMARÃES, H. G. O espaço existencial em xeque: uma odisseia para o espaço...

pelo próprio homem como seu mundo: o espaço existencial ou ontológico.

Para tal entendimento, da espacialidade, é que se torna premente a relação existencial-ontológica do homem com seus prolongamentos, do homem com seu mundo. E assim é que temos a análise do espaço como ser do homem, pela sua espacialidade prolongada como seu mundo. Sua condição de existência extrapola o corpo, não o abandonando, mas, expressando no mundo sua particularidade, e esta pode ser remetida como sentido de ser humano; extrapolando do seu corpo ao mundo, do todo na parte à parte no todo. Sendo a busca existencial-ontológica da espacialidade humana a base para a explicação do sentido de ser deste homem, é que nosso aparato se faz na ontologia. Principalmente na busca do sentido de ser da presença (Dasein) humana de Heidegger.

Ontologia ${ }^{7}$ é um tema proveniente da filosofia. Muitos consideram Parmênides de Eléa (nascido por volta de 530 antes da era cristã) como o "iniciador" da Ontologia. Principalmente em seu poema Sobre a Natureza (ou Acerca da Natureza), onde distingue entre o Ser e o Não Ser, fundando as bases da metafísica ocidental. Seu pensamento estabelecia "a necessidade de tomar as coisas em geral enquanto são, as coisas enquanto entes. E o ente não foi nem será senão o que é, ou seja, o seu ser" (MARTINS, 2007, p. 34), como a essência de todos os entes. Em Aristóteles (nascido em 384 antes da era cristã), o que chamou de "filosofia primeira" sendo depois chamado de metafísica buscou dois temas de estudo: o ser como ser (ou ente enquanto ente) e o ser ou ente por antonomásia, ou o ente ao qual estão subordinados os demais entes. Este como Deus (objeto geral da teologia) ${ }^{8}$.

Em alguns momentos, a disciplina "geral" de caráter formal foi novamente denominada "filosofia primeira" e, no inicio do séc. XVII, começou-se a se propor um nome para esse tipo de metafísica: seria a ontologia. Indo a historia desse termo, o primeiro que o usou na sua forma grega foi Rudolf Goclenius (1613), o que vinte e três anos depois passou a ser usado com mais frequência na transcrição latina, agora empregado por Abraham Calovius. Segundo este autor, a scientia de ente é chamada Metaphysica no que se refere à "ordem das coisas" e chama-se mais apropriadamente ontologia, quando diz respeito ao próprio tema ou objeto. Em 1642 J. Caramuel discorreu sobre o objeto da metafísica, que é o ens e chama-se ontologia porque é ontosophia, isto é, entis scientia. A ontologia foi introduzida como termo técnico em filosofia por Jean Le Clerc (ou lonannis Clericus), no segundo tratado, intitulado "Ontologia sive ente in genere" (1772). Le Clerc pode ser considerado um verdadeiro precursor de Wolff, este último foi quem sintetizou e popularizou a ontologia em 1730.

Este referencial é o que Mora (1996) veio a chamar de "pré-história" do termo ontologia permite compreender, entre outras coisas, que é notório que os autores que usaram "ontologia" ou "ontosofia" tenderam a destacar o caráter "primário" dessa ciência, em face de qualquer estudo "especial". Por isso, se a ontologia pôde continuar sendo identificada com a metafísica, o foi com uma metafísica geral e não com a "metafísica especial".

Partindo para o século XX, Edmund Husserl considerava a ontologia tanto como formal quanto material. A ontologia formal trata das essências formais (daquelas essências que convêm a todas as demais essências); a ontologia material trata das essências materiais e, constitui um conjunto de ontologias a que se dá o nome de ontologias regionais. A ontologia formal seria o fundamento de todas as ciências e a material, o fundamento das ciências dos fatos; mas, como todo fato participa de uma essência, toda ontologia material estaria fundada na ontologia formal (MORA, 1996). É a partir desse momento que tomamos as ideias de Martin Heidegger. Discípulo do pensamento de Husserl ${ }^{9}$ (tendo outros dois filósofos por ele influenciados: Sartre e Merleau-Ponty), irá basear-se no método fenomenológico de investigação, através do qual iria buscar a formulação de sua

7 A ontologia aflora então como uma busca pelo sentido de ser do ente-homem sem ser dado ou absoluto. O entendimento da existência humana é fruto de um questionar ontologicamente o ser do homem; sem a abstração metafísica. Contudo, como nosso viés de análise é calcado nas observações de fenômenos cotidianos, faz-se necessário a abordagem fenomenológica, ou melhor, uma análise fenomenológico-existencial da coexistência humana. Estes encraves dados pelas abstrações metafísicas serão analisados através e como fenômenos cotidianos, do processo de estereotipagem.

8 A metafísica oscilou desta forma, tradicionalmente entre ambos os temas de estudo. A primeira seria a "metafísica geral" que estudaria o ser ou ser "comuníssimo". A segunda chamada de "metafísica especial" estudaria temas como Deus, a alma, etc. Desta forma a necessidade de se distinguir esses dois temas de estudo (com nomes distintos) fez-se no séc. XVI.

9 "Fundador" da fenomenologia através dos estudos do "sistema total dos atos possíveis da consciência, das possíveis aparições, das significações que se relacionam precisamente com esses objetos", como uma "investigação transcendental" do mundo "no qual vivemos, nos movemos e estamos" (HUSSERL apud DARTIGUES, 2008, p. 65). 
GUIMARÃES, H. G. O espaço existencial em xeque: uma odisseia para o espaço...

ontologia fundamental. A sua base é a "questão do ser", mas tendo como base o método fenomenológico, sua ontologia será fenomenológica (DARTIGUES, 2008), ou melhor, uma analítica fenomenológico-existencial do Dasein $^{10}$, por isso existencial, pois somente o "Dasein humano" existe.

Após esse referencial geral, passemos para as nossas bases do pensamento de Heidegger. Mas antes, esclareçamos alguns termos essenciais para compreender ontologia. Sendo eles os seguintes: ser, ente, essência e existência.

O termo ser pode ser tomado como um verbo ou como um substantivo. No primeiro caso, pode ser considerado como expressão do processo que une um sujeito com um atributo ou, na sua forma intransitiva, como equivalente a existir. Ser é um dos vocábulos de mais difícil esclarecimento, por causa das suas diversificadas significações e também por causa das muitas interpretações que se têm dado a cada uma das suas significações. Às vezes, entende-se o ser como a essência; outras vezes, como a existência; outras, como o ente; outras ainda, como a substância. De fato, "'ser' não pode ser concebido como ente", o "'ser' não é um ente" (HEIDEGGER, 2008, p. 39), logo devemos compreender ser como a ação de ser, desse modo, "deve-se colocar a questão do sentido de ser", enquanto "o que determina o ente como ente" (HEIDEGGER, 2008, p. 40-41). Logo, se colocamos a questão do sentido de ser, é sempre sobre o sentido de ser de um ente. Ente é o como chamamos diversas coisas e em sentidos variados. "Ente é tudo de que falamos dessa ou daquela maneira, ente é também o que e como nós mesmos somos", e assim como Heidegger, a nossa análise vai à busca do sentido de ser do ente, mas de um determinado ente específico, "daquele que nós mesmos, os que questionam somos" (2008, p. 42-43). Buscamos então o modo ou sentido de ser do ente homem. Dando a esse sentido de ser um "caráter" espacial.

Para explicarmos essência ou existência, faz-se necessário um entendimento em conjunto. Até porque, a existência é o ser com o qual o ente se relaciona, e o ente que se relaciona com o ser é o existente humano, do qual tratamos como homem. E nesse sentido "a 'essência' da presença está em sua existência" (HEIDEGGER, 2008, p. 85), o que representamos como: a essência do ente homem está na sua relação com o ser, no seu movimento de dentro pra fora, do seu apresentar-se. Assim "a existência é a relação entre um existente e ela própria", i.e., "o surgimento de um existente na existência" (LÉVINAS,1998, p. 37), da qual podemos chamar de "a presença humana" (o Dasein) ${ }^{11}$, o que entendemos como existência humana.

Após estes esclarecimentos, busquemos uma relação com temas tratados na geografia que envolvam espacialidade e o tratamento de uma ontologia-existencial, para darmos prosseguimento ao entendimento da espacialidade do homem.

Indo em busca deste "espaço perdido", porque apartado, é que partimos em direção ao entendimento e à construção do conceito de espacialidade. Concordamos com Silva (2000, p. 20), em sua afirmação de que "o espacial possui sua própria ontologia específica" e que "cabe revelá-la", no qual a espacialidade emerge como existência espacial humana, do seu corpo, suas relações de fenômenos, de seu mundo e da manifestação dos homens no mundo e do homem como particularidade desses fenômenos. É a totalidade da relação parteconexão-todo. Busquemos tratar a espacialidade como a particularidade (a existencialidade como processo), no sentido de que jamais o ente humano deixou de fazer parte do espaço totalidade. Faremos assim um entendimento existencial da espacialidade e não existenciário, formulando então uma "existencialidade": a espacialidade como constituição de ser de um ente que existe.

10 A tradução deste termo cabal para a ontologia fenomenológica heideggeriana será explicitado brevemente depois, cabendo comentar que seus sentidos são dos mais variados e cabíveis de inúmeras confusões e conflitos de pensamento.

11 Este termo, como citado alhures, é a tradução referente ao Dasein, que preferimos e resumimos, sem muitos detalhes nesse momento, como existência humana. Em algumas traduções o termo assume a tradução de ser-aí, outras de estar-aí, outras como existência, e em outros momentos como simplesmente homem. É interessante observar que, em alemão não há distinção entre ser, estar, haver e existir, o que dificulta ainda mais a tradução. E ainda, compreender que ambos os sentidos, tanto de ser ou de estar, não significam em sentido absoluto "imobilidade", "enraizamento" ou qualquer termo semelhante. Ambos podem representar este caráter estático dependendo da situação, vejamos, se uma pessoa está morta, não significa que está "passageiramente" morta, a morte é um fato consumado. Se perguntarmos como algo vai ser, estamos remetendo não a uma fixidez, mas sim a uma das possibilidades. Utilizamos duas ideias para explicar a nossa escolha: 1) "O mundo, por conseguinte, pertence ao ser-aí humano, ainda que abarque todos os entes, também o ser-aí em sua totalidade" (HEIDEGGER, 1996, p. 126); e, 2) Presença "evoca o processo de constituição ontológica de homem, ser humano e humanidade. É na presença que o homem constrói o seu modo de ser" (HEIDEGGER, 2008, p. 561). Nesse entendimento a pre-s-ença humana é a existência humana, pois, abarca a relação que o ente homem (ença) tem com seu sentido de ser, que é a existência humana, o modo de ser de toda humanidade e de todo o mundo do homem como prolongamento de seu ato de ser. 
GUIMARÃES, H. G. O espaço existencial em xeque: uma odisseia para o espaço...

Na própria Geografia, viemos tratando com a ideia de espacialidade. Soja (1993) com "De volta à ontologia: da espacialidade existencial do ser", no qual discute a sua ideia de espacialidade, logo, este faz parte de um capítulo maior apontando de uma maneira geral sobre o termo. Moreira trabalha em dois momentos, de maneira implícita, pois seu tema geral não era este, no capítulo "Ser-Tões", de "Pensar e Ser em Geografia" (2007) e posteriormente, no começo de seu "Espacidades" (2008). Massey (2008), também situa a temática, mas com um viés anglófono tratado com "representações". E finalmente Lacoste (1997), com sua espacialidade diferencial.

É conveniente frisar que, em sua abordagem, Soja faz uma crítica à materialidade na conceituação do espaço. Relata que a espacialidade "nunca é primordialmente dada ou permanentemente fixa" (1993, p. 149). Traça estas ideias somente voltadas para aparências ou mensurações objetivas, fato este que se assemelha muito com a ideia de espacialidade como representação. Este é um reflexo da espacialidade externa de Descartes. Em seu retorno à ontologia, Soja propõe um diálogo, que visa ser central, sobre a "compreensão das estruturas da existência humana, do ser e, especialmente, no ser-no-mundo" (1993, p. 160-161). A abordagem do Geógrafo sobre o ser no mundo muito nos contempla, pois fará ligação com a existência humana, por propor uma existência no mundo. Fato muito importante é de sua citação sobre a alienação existencial como separação do mundo objetivo, casando o que seria a "fenomenologia existencial" da Filosofia (atribuindo a Heidegger e Sartre) com a teoria social no século $X X$.

Moreira, em suas duas passagens comentadas alhures, faz três citações acerca da espacialidade, tendo certa semelhança com Soja no que remete ao fundamento empírico do termo. Vejamos: a "apresentação/presentificação do ente na distribuição que torna a localização o elo de um ser-estar-algo do ente, o espaço-mundo virando espacialidade" (MOREIRA, 2007 , p. 157). Mais a frente, trata a espacialidade como "modo da existência do homem" (p. 158). No segundo momento, rapidamente repassa o termo colocando-se a espacialidade "como o estado empírico-concreto de organização da forma de existência espacial dos entes" (MOREIRA, 2008, p. 55). Ora, como comentamos, a sua base está no fundamento empírico do que vem a tratar como espacialidade. Deixando claro que o ente tratado é o homem, e que, a espacialidade dá-se como o modo de existência humana; contudo, a sua manifestação empírica dos fenômenos é o espaço-mundo, como mundo do homem.

Peguemos esta interlocução empírica do ser no mundo e do espaço-mundo. Façamos a leitura heideggeriana mais uma vez. Heidegger (2008, p. 102) afirma as seguintes ideias: "a 'espacialidade' do homem é uma qualidade de sua corporeidade (Leiblichkeit), fundada sempre num ser corpóreo (Körperlichkeit)", segue expondo que "a compreensão do ser-no-mundo como estrutura essencial da presença é que possibilita a visão penetrante da espacialidade existencial da presença". O ser no mundo funda-se como estrutura (espaço-mundo) da presença humana e, que sua compreensão, nos proporciona o entendimento da existência humana, que é a espacialidade. Essa espacialidade existencial humana no mundo, por ser uma estrutura também empírica, é fruto da prática dos homens, levando-nos a compreender que os fenômenos do espaço-mundo "por suas características e por seu funcionamento, pelo que ele oferece a alguns e recusa a outros, pela seleção de localização feita entre as atividades e entre os homens, é o resultado de uma práxis coletiva que reproduz as relações sociais" (SANTOS, 1978, p. 71). Essa espacialidade então é práxis, por externalizar uma espacialidade (extensão do homem-corpo) como espaço-mundo com uma "realidade" de fenômenos, no qual essa "realidade é realidade do homem e o mundo é projeção humana" (KOSIK, 1995, p. 246). Nos fenômenos do mundo do homem a espacialidade é práxis.

Esta realidade é ontológico-existencial e práxis, por ser relação do homem com seu ser em um "processo ontocriativo". Essa relação como criação humana, criação da própria espacialidade existencial e do seu próprio modo de ser no mundo. É o "modo específico de ser do homem" (KOSIK, 1995, p. 222): a espacialidade existencial humana como processo ontocriativo ${ }^{12}$. Este processo ontocriativo deve ser lido, acima de tudo, pelo entendimento do trabalho. Desde seu processo de humanização do homem, perpassando pela autocriação até o que se entendo por ser-estranho, com o trabalho alienado. Como o modo de ser no mundo criado pelo próprio homem se dá como realidade empírica, a perda de referência espacial também se deu na prática, e não somente no campo das ciências, com o estatuto lógico do espaço. A espacialidade que apreendemos nos fe-

12 A particularidade da existência humana, convergindo numa espacialidade como processo ontocriativo em nosso entendimento. 
GUIMARÃES, H. G. O espaço existencial em xeque: uma odisseia para o espaço...

nômenos cotidianos é a de objetos, esses objetos como corpos ocupam lugar no espaço, assim como nós, não há relação de pertencimento. Este entendimento empírico, fenomênico e cotidiano é fruto do ser-estranho do homem através do trabalho alienado. E para este esclarecimento, cabe fazermos uma releitura das ideias marxianas sobre trabalho e homem, casadas com a ontologia-existencial deste último.

Como então, o homem se fez ontologicamente apartado de si mesmo como indivíduo e como espécie, dos outros seres vivos e de sua espacialidade?

Faremos com uma rápida abordagem a tomada desse sentido de ser estranho através da base para esse desfecho: o trabalho. Este será abordado como um processo perpassando três fases: 1) o trabalho humano como humanização do homem; 2) o processo do trabalho social como autoprodução; e, 3) o trabalho alienado como alienação do trabalho humano e de seu sentido de ser.

Pelo que sabemos baseado em Engels (2000), o trabalho é uma categoria de entendimento da "mecânica matemática", como medida de movimento dos corpos advindo das concepções de Descartes. Este fez a "medida geral do movimento", conduzindo a ideia de que "uma lei semelhante rege diversos outros casos de movimento de corpos unidos em um mesmo sistema" (ENGELS, 2000, p. 57), pois bem, temos aí o trabalho. Não é por acaso que a sua interpretação por Marx e Engels irá convergir para uma ideia de humanização do(s) homem(ns) através do trabalho. Resumindo: é uma medida geral que movimenta os homens (corpos) unidos em um mesmo sistema, que é a humanização do homem. Nesse sentido é que Engels irá escrever um breve texto com o título "Humanização do macaco pelo trabalho". Vejamos uma citação de Engels por Smith que mais se aproxima da nossa ideia: "O trabalho, ele dizia, é a 'condição básica primeira para toda a existência humana, e isso ganha uma tal amplitude que, em certo sentido, podemos dizer que o trabalho criou o próprio homem'” (SMITH, 1988, p. 74), ou seja, a existência (presença) humana é produto do trabalho humano, um processo ontocriativo de humanização do homem. Que nessa relação já não é mais macaco, a autocriação da corporeidade humana.

No momento de "hominização do homem" (MOREIRA, 2007, p. 157) é o processo metabólico do trabalho, modificando a natureza humana e nesse processo, surge o primeiro momento da desespacialização da espacialidade humana, a desnaturização. Este é um "processo em que o ser humano com sua própria ação, impulsiona, regula e controla seu intercambio material com a natureza. Defronta-se com a natureza como uma de suas forças. Poe em movimento as forças naturais de seu corpo, braços e pernas, cabeça e mãos, a fim de apropriar-se dos recursos da natureza, imprimindoIhes forma útil à vida humana. Atuando assim sobre a natureza externa e modificando-a, ao mesmo tempo modifica sua própria natureza" (MARX, 1988, p. 202). E assim começa "a separação convencional e sacrossanta da natureza e da sociedade" (MARX, 1988, p. 20), o homem se vê "extraído do convívio do espaço da natureza, o homem é então esvaziado de suas propriedades ontológicas mais profundas" (MOREIRA, 2007, p. 135). O espaço biológico que antes era sua espacialidade plena começa a sofrer rupturas.

Este é o segundo momento do metabolismo do processo do trabalho humano. Este vai se conformando como um movimento autopoiético, num sentido mais integral, vai tornando-se medida geral do movimento, integrando as relações sociais, transformando o trabalho humano num trabalho social coletivo. O sentido de ser deste homem vai se tornando cada vez mais social, o homem ontologicamente como ser-social. O processo do trabalho social vai se conformando como um movimento de transformar o homem em uma "criatura genérica" e universal. "A universalidade do homem aparece praticamente na universalidade que faz de toda a natureza seu corpo inorgânico". Como vida criando vida, o trabalho "aparece agora para o homem como o único meio que satisfaz uma necessidade, a de manter a existência física" (MARX, 2006, p. 115-116). Assim temos o segundo processo de desespacialização da espacialidade humana, a desterreação, como "expropriação que retira do homem sua fonte de vida e o lança na condição de dependente do mercado como uma peça banal" (MOREIRA, 2007, p. 136).

O derradeiro momento do processo do trabalho é o mais cruel e universal, o processo do trabalho se transforma em trabalho alienado. É o estranhamento de tudo que é advindo do processo do trabalho. O trabalho alienado transforma a "vida genérica do homem", que se autoproduziu, "em ser estranho, em meio da sua existência individual", ainda "aliena do homem o próprio corpo", aliena o homem que agora é trabalhador, conhecido por seus ofícios (que desconhece os outros), do produto do seu trabalho que pertence a outro homem, e o trabalho alienado é "a alienação do homem em relação ao homem" (MARX, 2006, p. 117-118). Assim completou-se o círculo, a existência humana agora é abstrata, no qual ele é simplesmente homem que trabalha. O espaço biológico totalmente apartado, agora, "o homem deve comer para trabalhar e deve trabalhar para comer" (ARENDT, 2007, p. 156). Este homem que trabalha se torna homem-mercadoria alienado e este se 
torna seu sentido de ser, ser estranho; ao mundo que é o mundo do homem, de si mesmo, do produto de seu trabalho, da sua espacialidade (somente em potência) e dos outros homens ${ }^{13}$. Fecha-se o ciclo da desespacialização, a desterritorialização, em constante processo de conflitos intrapessoais, interpessoais, inter-regionais, globais em todos os sentidos de referência da vida, que agora é mercadoria: em todos os sentidos.

E nesse sentido amplo do ser do homem, de sua existência abstrata, é que emerge a subjetividade na espacialidade. No sentido de que os fenômenos cotidianos formarão o cabedal de relações, formas e corporeidades, através do que tratamos como subjetividade do ser. O sentido da copresença cotidiana do mundo do homem, o ser no mundo, é calcado em aspectos subjetivos, i.e., a decadência da existência humana. O sentido de ser estranho se configura no cotidiano através da decadência, onde nos sentimos angustiados, loucos para seguirmos na moda, nos prendendo a padrões de comportamentos estranhos a nós mesmos, vindos de outrem que nem conhecemos que padronizam o "corpo", as roupas, o modelo de homem universalmente aceito. "Na angústia - dizemos nós - 'a gente sente-se estranho'" (HEIDEGGER, 1996, p. 56). É uma existência humana in-sistente, que nos esconde a verdade através da subjetividade deste sentido de ser. Este ser nos é apresentado cotidianamente como um "mal de ser" (LÉVINAS, 1998, p. 23).

O espaço cotidiano (fenomenológico) é a dimensão onde "se distribuem elementos nas relações de coexistência" (CERTEU, 2002, p. 201), nesta cotidianidade, da subjetividade na espacialidade, é que se dá o "acontecer fenomenológico do ser do ente" (HEIDEGGER, 1996, p. 111). É na cotidianidade que desperta o ser com. Este ser com os outros, através do qual a mundanidade do ser no mundo é cotidianidade, sendo através dos fenômenos que despertamos e reproduzimos a subjetividade desse nosso sentido de ser estranho.

Os preconceitos afloram: racismo, sexismo, uma moda que modela o corpo e não o corpo que faz a moda. Devemos ficar magros para caber na roupa, nos transportes públicos. Devemos estar magros para sermos "bem vistos", estarmos assim "de bem com nossa aparência". Não esqueçamos: não existe o homem médio, universal! Cada um é autêntico na sua existência, mas infelizmente a coexistência é estranha e "universalizante". Nesse sentido é que emerge o "processo de estereotipagem" (HARVEY, 2006, p. 168), moldados em padrões médios estranhos a nós, que reproduzimos subjetivamente em nosso ser com os outros. Porém não aceitamos os outros! Perdemos o nosso bem-estar corporal numa moda uniformizante, em padrões de beleza, que julgam os outros pelo que têm, o que vestem, o que podem comprar, pelo seu cabelo. Este último um fenômeno bizarro de perda total de juízo estético, que transcende para o de moral. O processo de estereotipagem aparta ainda mais o espaço-corpo, o homem-corpo é um homem modalizado, modelizado, um homem que se quer universal (não é por acaso que existem os "modelos"!).

Assim finalizamos a nossa abordagem existencial do espaço na Geografia. Uma busca de análise fenomenológico-existencial da espacialidade humana, estranha do homem porque criada por ele mesmo. Estranha através das ideias e das práticas diárias, mas totalmente possível de ser desvelada, pois, nunca deixou de existir.

\section{CONSIDERAÇÕES FINAIS: PARA MUDANÇAS DE NOSSA PRÁTICA COTIDIANA}

É desta forma que pretendemos contribuir, para uma análise menos "recortada" e "intimista" na Geografia. Buscando um espaço, uma espacialidade existencial humana plena, porque remetendo às suas origens de estranhamento. Cabe então responder a nossa questão central: podemos entender o espaço como ser? Esperamos que seja uma resposta concordante. Pois como pudemos ver, nessa resumida exposição, o espaço tem sido uma grande problemática em nosso ser no mundo. Na Filosofia, nas ciências, na Geografia, no mundo do homem e em nosso ser com os outros. Como conceito, representação do sentido comum e categoria da existência. O espaço é apartado de todos nós, porque

13 O "trabalho alienado" transforma o homem em trabalhador, fazendo-o descer "até o nível de mercadoria, e miserabilíssima mercadoria" (MARX, 2006, p. 110). Estes homens são simples mercadorias, na mão de outros homens. O processo de trabalho transformando o mundo do homem em mundo totalmente estranho a ele mesmo. Produz um homem estranho à sua condição, e este homem, "o trabalhador além de estar alienado do produto do seu trabalho, está também alienado da sua identidade com o semelhante (ser social), não se reconhecendo mais como proletário, mas como bancário, motorista, químico, professor, etc." (THOMAZ JÚNIOR, 2002, p. 10). 
GUIMARÃES, H. G. O espaço existencial em xeque: uma odisseia para o espaço...

somos apartados principalmente da natureza, de nós mesmos e dos outros!

Esta nossa abordagem de uma fenomenologia existencial-ontológica, relacionada com o a Geografia, busca ser uma contribuição, mesmo que mínima para a mudança deste mundo do homem, e, principalmente, deste homem. Assim ficamos com Marx (2006, p. 186), no que "a minha verdadeira existência humana é a minha existência na filosofia", esta "espécie de competência capaz de perscrutar o ente, a saber, sob o ponto de vista do que ele é, enquanto ente" (HEIDEGGER, 1996, p. 34), e este ente-existente que é o homem que se deve investigar rigorosamente. Junto a este homem, o seu mundo, cabe a nós, Geógrafos, mudá-lo ou pelo menos ajudar a mudá-lo e não somente interpretá-lo ${ }^{14}$. Nesse sentido de autoavaliação crítica é que a Geografia deve deixar de ser, ainda, um protótipo de disciplina simplória e enfadonha, conforme critica Lacoste (1997), como um '“pequeno mundo' no qual vivem apenas professores, geógrafos profissionais e estudantes, olhando circunspectos e orgulhosos o seu próprio umbigo" (SILVA, 1983, p. 134). Ora, devemos ir à origem filosófica em sentido ontológico do homem, do mundo, das ciências e da Geografia. Esperamos que na Geografia exista o lugar para a busca, que haja lugar para as ideias. Como tratou Quaini (2002, p. 25), "Geografia e filosofia: a aproximação das duas disciplinas é hoje vista pelo geógrafo como um fato que, no máximo, pode ter um interesse histórico", e isto parece ser uma máxima ainda hoje.

Sabemos que a noção de espaço realmente não define a Geografia, principalmente o espaço lógico da ciência Geográfica. Por isso busquemos o ser (espaçotempo em movimento) e a existência. Sem dicotomias, para uma Geografia Filosófica e realmente libertadora. Espero que compreendamos a nossa existência como espacialidade, nesse Espaço como Totalidade. Este é o nosso recado, para que com cada análise crítica "a geografia mude sem ficar a mesma coisa" (SANTOS, 2005), mudando nossas concepções academicistas, profissionais por demais, que seguem num ser estranho de nossa própria existência. E para que nossa existência espacial mude ao mudarmos a nós mesmos.

\section{REFERÊNCIAS}

ARENDT, Hannah. A Condição Humana. Rio de Janeiro: Forense Universitária, 2007.

BRUNHES, Jean. Geografia Humana (edição abreviada). Rio de Janeiro: Fundo de Cultura, 1962.

CAMARGO, Luís H. Ramos. A ruptura do meio ambiente: conhecendo as mudanças ambientais do planeta através de uma nova percepção da ciência: a geografia da complexidade. Rio de janeiro: Bertrand Brasil, 2005.

CERTEU, Michel de. A invenção do cotidiano: artes de fazer. Petrópolis: Vozes, 2002.

CLAVAL, Paul. A nova Geografia. Coimbra: Livraria Almedina, 1982.

CORREAA, Roberto Lobato. Espaço: um conceito-chave da Geografia. In: CASTRO, Iná Elias de; GOMES, Paulo César da Costa; CORREAA, Roberto Lobato. Geografia: conceitos e temas. Rio de Janeiro: Bertrand Brasil, 2003.

DARTIGUES, André. O que É a fenomenologia? São Paulo: Centauro, 2008.

ENGELS, Friedrich. A dialética da Natureza. São Paulo: Paz e Terra, 2000.

GEORGE, Pierre. Sociologia e Geografia. Rio de Janeiro: Forense, 1969.

Problemas, doutrina e método. In: GEORGE, Pierre; GUGLIELMO, Raymond; LACOSTE, Yves; KAYSER, Bernard. A Geografia ativa. São Paulo: Difusão Européia do Livro, 1973.

GOULART GUIMARÃES, Humberto. Ensaio sobre o espaço como modalidade ontológica do ser: nos caminhos de Armando Corrêa da Silva. Revista Discente Expressões Geográficas, n. 5, ano V, p. 31-48, 2009. Disponível em: <http://www. geograficas.cfh.ufsc.br/>. Acesso em: junho de 2009.

HARTSHORNE, Richard. Propósitos e natureza da Geografia. São Paulo: Hucitec, 1978.

O conceito de Geografia como uma ciência do espaço, de Kant e Humboldt para Hettner. Caderno Prudentino de Geografia, Presidente Prudente, n. 28, p. 9-33. 2006.

HARVEY, David. A Justiça Social e a Cidade. São Paulo: Hucitec, 1980.

14 A citação brilhante de Harvey expressa para nós esta busca crítica de mudança na práxis cotidiana, onde, "a pessoa é dotada de certas capacidades e habilidades passíveis de ser usadas para transformar o mundo. [...] Ao mudar nosso mundo, mudamos a nós mesmos. Como, então, pode algum de nós falar de mudança social sem ao mesmo tempo estar preparado, em termos tanto mentais como físicos, para alterar a si mesmo? Inversamente, como poderemos transformar a nós mesmos sem transformar nosso mundo?" (HARVEY, 2006, p. 307). 
GUIMARÃES, H. G. O espaço existencial em xeque: uma odisseia para o espaço...

. Espaços de Esperança. São Paulo: Loyola, 2006.

HEIDEGGER, Martin. Conferências e escritos filosóficos. São Paulo: Nova Cultural Ltda., 1996. (Coleção: Os Pensadores)

Ser e Tempo. Petrópolis: Vozes, 2008.

KANT, Immanuel. Crítica da razão pura. Edições e publicações Brasil editora S.A.: São Paulo, 1965.

. Introdução à Geografia. Revista GEOgraphia, Niterói: PPGEO/UFF, ano IX, n. 17, p. 121-130, 2008 .

Crítica da faculdade do juízo. Rio de Janeiro: Forense Universitária, 2008b.

KOSIK, Karel. Dialética do concreto. São Paulo: Paz e Terra, 1995.

LACOSTE, Yves. A Geografia. In: CHÂTELET, François. História da Filosofia. Lisboa: Dom Quixote, 1977.

A Geografia: isso serve, em primeiro lugar, para fazer a guerra. Campinas: Papirus, 1997.

LÉVINAS, Emmanuel. Da existência ao existente. Campinas: Papirus, 1998.

LIMA, Elias L. A Reinvenção da Corporeidade: por uma teoria do sujeito em Geografia. Trabalho apresentado no 7. Encontro Nacional da ANPEGE: Espacialidades Contemporâneas: o Brasil, a América Latina e o Mundo, Niterói, 2007a.

A Reinvenção da Corporeidade: o cotejo entre a tradição moderna e a tradição indígena. 2007. Dissertação (Mestrado em Geografia) - Niterói: UFF, 2007b.

. Do corpo ao espaço: contribuições da obra de Maurice Merleau-Ponty à análise geográfica. Revista GEOgraphia. Niterói: PPGEO/UFF, ano IX, n. 18, p. 65-84, 2008.

MASSEY, Doreen. Pelo espaço. Rio de Janeiro: Bertrand Brasil, 2008.

MARTINS, Élvio. Lógica e espaço na obra de Immanuel Kant e sua gênese e contribuição para a Geografia. Revista GEOgraphia. Niterói: PPGEO/UFF, ano V, n. 9, p. 41-66, 2003.

Geografia e Ontologia: o fundamento geográfico do ser. Espaço e Tempo, n. 21, p. 33-51, 2007.

MARX, Karl. O Capital: crítica da economia política. Livro 1, volume 1. Rio de Janeiro: Bertrand Brasil, 1988.

Claret, 2006

Manuscritos econômico-filosóficos. São Paulo: Martin

MERLEAU-PONTY, Maurice. Fenomenologia da percepção. São Paulo: Martins Fontes, 2006.

MORA, José Ferrater. Dicionário de Filosofia. São Paulo: Martins Fontes, 1996.

MOREIRA, Ruy. O Discurso do Avesso (para a crítica da Geografia que se ensina). Rio de Janeiro: Dois Pontos, 1987.
A Diferença e a Geografia. O ardil da identidade e a representação da diferença na Geografia. Revista GEOgraphia. Niterói: PPGEO/UFF, ano I, n. 1, 1999.

Marxismo e Geografia: a geograficidade e o diálogo das ontologias. Revista GEOgraphia. Niterói: PPGEO/UFF, ano VI, n. 11, p. 21-38, 2004.

Sociabilidade e Espaço: as formas de organização geográfica das sociedades na era da terceira revolução Industrial - um estudo de tendências. AGRÁRIA. São Paulo, n. 2, p. 93-108, 2005, Disponível em: <http://www.geografia. fflch.usp.br/revistaagraria/revistas/2/moreira_r.pdf>. Acesso em: junho de 2009.

2007.

Pensar e Ser em Geografia. São Paulo: Contexto,

Espacidades: uma reflexão sobre o problema da Ontologia do espaço. In: OLIVEIRA, Márcio P.; COELHO, Maria C. N.; CORREAA, Aureanice de M. O Brasil. A América Latina e o Mundo: Espacialidades contemporâneas (I). Rio de Janeiro: Lamparina: Anpege, Faperj, 2008.

QUAINI, Massimo. Marxismo e Geografia. Rio de Janeiro: Paz e Terra, 2002.

RECLUS, Elysée. Elysée Reclus. São Paulo: Ática, 1984. (Série: Grandes cientistas sociais)

SANTOS, Milton. Por uma Geografia Nova: da crítica da Geografia a uma Geografia Crítica. São Paulo: Hucitec, 1978.

Espaço e Método. São Paulo: Studio Nobel, 1985.

. Metamorfoses do Espaço Habitado. São Paulo: Hucitec, 1988a.

O espaço geográfico como categoria filosófica. Revista Terra Livre, n. 5, p. 9-20, 1988b.

Edusp, 2003.

Economia Espacial: críticas e alternativas. São Paulo:

Para que a geografia mude sem ficar a mesma coisa. R. RA'E GA, Curitiba, n. 9, p. 125-134, 2005. Editora UFPR, Disponível em: <http://ojs.c3sl.ufpr.br/ojs2/index.php/raega/ issue/view/358/showToc>. Acesso em: junho de 2009.

. A Natureza do Espaço: técnica e tempo, razão e emoção. São Paulo: Edusp, 2006.

2007.

Pensando o Espaço do Homem. São Paulo: Edusp,

SILVA, Armando Corrêa da. O Espaço como Ser: uma autoavaliação crítica. In: MOREIRA, Ruy (Org.). Geografia: teoria e crítica (o saber posto em questão). Petrópolis: Vozes, 1982.

. A renovação Geográfica no Brasil - 1976/1983 (As geografias crítica e radical em uma perspectiva teórica). Boletim Paulista de Geografia, n. 76, 1983.

. As categorias como fundamentos do conhecimento 
GUIMARÃES, H. G. O espaço existencial em xeque: uma odisseia para o espaço...

geográfico. In: SANTOS, Milton; SOUZA, Maria Adélia de (Org.). Espaço Interdisciplinar. São Paulo: Nobel, 1986.

. O espaço fora do lugar. São Paulo: Hucitec, 1988.

Sujeito e objeto e os problemas da análise. Boletim Paulista de Geografia, n. 71, 1992.

A aparência, o ser e a forma. Revista GEOgraphia: PPGEO/UFF, Niterói, ano II, n. 3, p. 7-25, 2000.

SMITH, Neil. Desenvolvimento desigual. Rio de Janeiro: Bertrand Brasil, 1988.
SOJA, Edward W. Geografias Pós-Modernas: a reafirmação do espaço na teoria social crítica. Rio de Janeiro: Zahar Editores, 1993.

SOUSA SANTOS, Boaventura. Um discurso sobre as ciências. Porto: Edições Afrontamento, 2002.

SOUZA, Marcelo Lopes de. Espaciologia: uma objeção. Anuário do Instituto de Geociências, v. 10, p. 72-93, 1986.

THOMAZ JÚNIOR, Antonio. Por uma geografia do trabalho. Revista Pegada Eletrônica, n. 3 (número especial), 2002, Disponível em: <http://www4.fct.unesp.br/ceget/v3neago2002. htm>. Acesso em: junho de 2009. 